\title{
Identificación sanitaria: la huella genética
}

\author{
Marqués Negredo Mª. ${ }^{1}$, Sanz Zamarro Mar. ${ }^{2}$, Villa Rodriguez L. ${ }^{3}$, García Tejerina R. ${ }^{3}$, Álvarez-Maldonado \\ Paramés T. ${ }^{1}$, Rubiano Rubiano JC. ${ }^{4}$, Coca Menchero S. ${ }^{5}$
}

Sanid. mil. 2011; 67 (3): 317-320; ISSN: 1887-8571

\section{RESUMEN}

Hasta hace poco, la identificación de los restos de las personas desaparecidas se basaban en comparar la información que se tenía de esas personas antes y después de la desaparición o la catástrofe. Hoy en día se ha introducido el análisis del ADN para la completa y fiable identidad de dichas personas. La variabilidad del genoma y la identificación de esa variabilidad a través del estudio de diversos polimorfismos (RFLP, SNP, etc) hacen que cada individuo se pueda separar de su semejante con un alto grado de fiabilidad (99'999 \%) y al mismo tiempo se puede seguir su linaje. Estas técnicas han sido sometidas a procesos de validación y están altamente automatizadas. El sistema «AmpFlSTR ${ }^{\circledR}$ Identifiler ${ }^{\mathrm{TM}}$ PCR Amplification Kit» junto con el equipo «ABI Prism ${ }^{\circledR} 3130$ Genetic Analyzer» de Applied Biosystems permiten la identificación de 15 loci más un marcador de sexo (amelogenina). El sistema CODIS está constituido por 13 STRs de los 15 que analiza este kit.

PALABRAS CLAVE: Polimorfismos de ADN, STR, AmpFlSTR, huella genética.

\section{Medical identification: genetic fingerprint SUMMARY}

Until recently the identification of human remains was based on comparing the data available of the missing persons before and after their disappearance or the disaster. Nowadays DNA analysis allows complete and reliable identification. The variability of the genome and the identification of that variability through the study of different polymorphisms (RFLP, SNP, etc) facilitate the differentiation of individuals with a high degree of reliability (99.999\%) and simultaneously follow their lineage. These techniques have been validated and are highly automated. The system «AmpFlSTR ${ }^{\circledR}$ Identifiler ${ }^{\mathrm{TM}}$ PCR Amplification Kit», together with the «ABI Prism ${ }^{\circledR} 3130$ Genetic Analyzer» of Applied Biosystems, allows the identification of 15 loci and one sex marker (amelogenin). The CODIS system is integrated by 13 STRs among the 15 analyzed by this kit.

KEY WORDS: DNA polymorphisms, STR, AmpFISTR, Genetic fingerprint.

El análisis de ADN para la identificación de evidencias humanas en el campo forense se hizo popular a partir de mediados de la década de los 90 . Se analizan pequeñas regiones o trozos de la secuencia del ADN que se encuentran repetidos y dispersos por todo el genoma ${ }^{1}$. Al ser tan pequeñas están libres de artefactos como la presencia de dímeros entre las bases nitrogenadas o alteraciones de la hélice del ADN en ese tramo, por ejemplo, lo que minimiza los errores de lectura al copiarse, son fáciles de amplificar y están poco degradadas aunque la muestra sea mala o escasa. Además son regiones de $\mathrm{ADN}$ ampliamente polimórficas, por lo que varían de un individuo a otro haciendo muy difícil su coincidencia y no están relacionadas con patologías, lo que elimina susceptibilidades a la hora de establecer un perfil genético.

El ADN o ácido desoxirribonucleico se encuentra fundamentalmente en el núcleo de las células eucariontes. También se puede

${ }^{1}$ Lda. en Biología (Genetista). Servicio de Anatomía Patológica. Unidad de Identificación Sanitaria.

${ }^{2}$ Dra en Biología (Genetista). Servicios Centrales.

${ }^{3}$ Tte. Enfermera. Servicio de Anatomía Patológica. Unidad de Identificación Sanitaria.

${ }^{4}$ Auxiliar de Enfermería. Servicio de Anatomía Patológica. Unidad de Identificación Sanitaria.

${ }^{5}$ Col. Médico. Servicio de Anatomía Patológica.

Hospital Central de la Defensa Gómez Ulla. Madrid.España.

Dirección para correspondencia: $M^{a}$ Luisa Marqués Negredo. Servicio de Anatomía Patológica. Hospital Central de la Defensa Gómez Ulla. Glorieta del Ejército, s/n. 28047 - Madrid. Tno:914222547.mmarneg@oc.mde.es

Recibido: 28 de octubre de 2010

Aceptado: 13 de enero de 2011 hallar ADN en el interior de las mitocondrias, en los cloroplastos de las células vegetales y en el citoplasma de las células procariotas. Asimismo podemos encontrar ácidos nucleicos de origen viral ${ }^{2}$.

Podemos clasificar el ADN en:

1. Genes que codifican proteínas y se transcriben a ARN mensajeros.

2. Genes que transcriben ARN mensajero y transferente.

3. Genoma no codificante: DNA repetido, DNA espaciador y pseudogenes.

El genoma ${ }^{2}$ es el conjunto total de material genético hereditario presente en una célula. La parte codificante del genoma, incluida en los genes, posee la información necesaria para dar lugar a los productos génicos: los RNAs y las proteínas que son los responsables de toda la actividad celular, de sus características morfológicas y de muchas de las claves del comportamiento de un organismo, desde la embriogénesis a su crecimiento, maduración física e intelectual, estado adulto, reproducción y todas sus funciones metabólicas y actividades fisiológicas.

El ADN genómico nuclear es una entidad altamente variable. Esta diversidad es responsable de fenómenos como la evolución de las especies y, dentro de una misma especie, de la presencia de características diferenciales para cada individuo, únicas e irrepetibles.

La variabilidad genética se observa en variaciones en la secuencia del genoma producidas por diferentes mecanismos. Estas varia- 
ciones afectan tanto a regiones codificantes como a las no codificantes del genoma. En ambos casos pueden consistir en la variación de un solo par de bases del ADN o de varios pares de bases. A su vez, cualquier variación puede tener lugar en las células reproductoras, con lo que será transmitido a la descendencia, o bien se puede producir en células somáticas, sin repercusión en la descendencia (como los polimorfismos que ocurren en la mayoría de los cánceres).

Hoy en día polimorfismo ${ }^{2,3}$ se define como la existencia simultánea de una población de genomas con distintos alelos para un locus determinado. Un polimorfismo es considerado como tal cuando su frecuencia en la población es superior al $1 \%$. Los alelos son variaciones de la secuencia de $\mathrm{ADN}$ presente en un locus. Un locus es una posición definida en un cromosoma. Consecuentemente, en una célula diploide (dotación doble de ADN; ejemplo: paterno y materno) cada locus está ocupado por dos alelos, uno de origen paterno y otro de origen materno. Por lo tanto, individuos heterocigotos para un $l o-$ cus concreto serán aquellos que muestran dos alelos con diferentes secuencias en ese locus, e individuos homocigotos serán aquellos que han heredado el mismo alelo (misma secuencia) de cada progenitor.

Como todo polimorfismo es el reflejo del genotipo de los individuos, surge el concepto de individualidad genética, entendida como la presencia en todo individuo de un genoma con una secuencia característica y única para ese individuo. Dentro de una misma especie, en este caso la humana, la huella genética trata de determinar la individualidad genética analizando polimorfismos, que pueden ser fisiológicos o normales y patológicos.

\section{MECANISMOS IMPLICADOS EN LA VARIABILIDAD GENÉTICA}

Son varios los mecanismos que producen variabilidad genética y normalmente no actúan por separado. Actúan desde la morfogénesis y durante toda la vida del individuo ${ }^{2,4}$. La causa última del polimorfismo es la existencia de mutaciones en el ADN.

\section{CONSECUENCIAS FUNCIONALES DEL POLIMORFISMO ${ }^{2}$}

El polimorfismo puede tener distinta transcendencia desde el punto de vista funcional, dependiendo de la región de $\mathrm{ADN}$ a la que afecte.

\section{Polimorfismos en regiones génicas codificantes}

De la parte codificante del genoma humano (de 20.000 a 25.000 genes según el estudio del genoma humano) se cree que unas tres cuartas partes son genes monomorfos, esto es, genes únicos compartidos sin variación por todos los individuos. Son el genoma común de la especie humana. La cuarta parte restante son polimorfos y sus variaciones determinan el polimorfismo génico.

\section{Polimorfismos en regiones génicas no codificantes}

Existen regiones dentro de los genes que no se traducen en su producto génico. Aunque este polimorfismo no afecte a la secuencia de la proteína, sí puede afectar a su expresión.

\section{Polimorfismos en regiones no génicas}

No tienen efecto en el fenotiopo. Sin embargo sí son de interés para la identificación genética de individuos.

\section{Polimorfismos en el genoma mitocondrial}

En el genoma mitocondrial ${ }^{2}$ más del $93 \%$ de la molécula del ADNmt es codificante. Además, el ADNmt es marcador de linaje puesto que las mitocondrias son heredadas por vía materna.

\section{APLICACIONES DE LOS POLIMORFISMOS DE ADN}

1. Los polimorfismos del ADN que no tienen efecto fenotípico se utilizan para la comprobación de la identidad (huella genética).

2. Los polimorfismos que tienen una contribución mínima o leve a la susceptibilidad frente a ciertos procesos patológicos poseen interés médico especialmente en la prevención de enfermedades complejas.

3. Y los polimorfismos que desempeñan un papel directo en la aparición de una patología son de interés para establecer un diagnóstico o un seguimiento de la enfermedad del paciente, así como para el estudio de los mecanismos moleculares de la enfermedad.

\section{¿CÓMO SE HACE LA HUELla GENÉTICA?}

Desde la correcta recepción de la muestra hasta la elaboración del informe médico-legal, el proceso consta de una serie de etapas.

\section{Extracción del ADN}

De cualquier muestra orgánica se puede extraer ADN: de un resto humano como un diente, pelo, sangre, saliva, semen, etc. En nuestro caso, y como método más cómodo y seguro de almacenar vestigios biológicos para determinación a posteriori de ADN, se utilizan muestras de sangre recogidas en unas tarjetas tratadas con una química especial. Las FTA ${ }^{\circledR}$ Cards de Whatman ${ }^{\circledR}$ son unas tarjetas que están impregnadas con una fórmula química patentada que lisa las membranas celulares y desnaturaliza las proteínas al contacto. Los ácidos nucleicos quedan físicamente atrapados, inmovilizados y estabilizados para que puedan ser almacenados a temperatura ambiente. Las FTA's protegen a los ácidos nucleicos de las nucleasas, de la oxidación, del daño de las radiaciones UV y de ataques de microbios y hongos. Los patógenos infecciosos quedan inactivados por contacto con las FTA's. Los ácidos nucleicos quedan estabilizados durante años.

Nuestras muestras se recogen en la Unidad de Identificación Sanitaria dentro del Servicio de Anatomía Patológica del Hospital Central de la Defensa «Gómez Ulla»de Madrid, en tarjetas «Gene Storage Matrix ${ }^{\mathrm{TM}}$ » que están personalizadas para el Ministerio de Defensa. Éstas se fabrican en entorno GMP sala blanca 10,000/100,000 bajo estándares ISO9001:2002 y aprobado por FDA para dispositivos médicos de Clase III. Son de Control Biogen, S. L.. 
De las tarjetas se extrae un disco de $2 \mathrm{~mm}$ de los cuales se puede conseguir entre 10 y $30 \mathrm{ng}$ de ADN. Sobre el ADN de este disco se aplica la amplificación de las secuencias que vamos a identificar para establecer el perfil genético.

\section{Cuantificación del ADN}

Cuando las muestras no se han recogido en soportes tipo FTA, es conveniente hacer una cuantificación del ADN obtenido.

En nuestro laboratorio la cuantificación se lleva a cabo mediante una reacción de PCR a tiempo real. Se realiza una curva patrón de referencia sobre la que se va a extrapolar la concentración de ADN de la muestra. Para que la cuantificación sea óptima se deben tener en cuenta una serie de valores de la prueba (pendiente de la curva patrón, R2, línea basal, ruido de inicio,... $)^{5}$. Es un paso importante ya que se necesita saber con qué cantidad de ADN se está trabajando a fin de que las posteriores reacciones de PCR y análisis de fragmentos salgan bien.

\section{Amplificación del ADN}

La PCR o reacción en cadena de la polimerasa, es una técnica de amplificación in vitro de pequeños segmentos de $\mathrm{ADN}$ con la que a partir de una única copia de ADN podemos obtener millones de copias. Los cebadores o primers empleados están marcados con diferentes fluorocromos (6-FAM $\left.{ }^{\mathrm{TM}}, \mathrm{VIC}^{\circledR}, \mathrm{NED}^{\mathrm{TM}}, \mathrm{PET}^{\circledR}\right)$ para obtener fragmentos marcados. El «AmpFISTR ${ }^{\circledR}$ Identifiler $^{\mathrm{TM}}$ PCR Amplification Kit» proporciona primers para amplificar 16 STR que son coamplificados en un mismo tubo para cada muestra ${ }^{5-10}$.

\section{Análisis de secuencias de ADN}

Los polimorfismos que podemos analizar son de distintos $\operatorname{tipos}^{(3,11,12)}$ :

- Polimorfismos de longitud de fragmentos de restricción (RFLP).

- Polimorfismos en el número de repeticiones en tándem (VNTR y STR).

- Polimorfismos de secuencia (SNP).

En el caso de la huella genética se detectan y analizan STR ${ }^{1}$ Los STR o microsatélites aparecen en el ADN no codificante repetitivo $^{2,4}$. Son repeticiones de secuencias de entre 1 y 7 pares de bases colocados en tándem. Son altamente polimórficos y de herencia mendeliana simple. Las grandes ventajas de los STR son su estabilidad y la posibilidad de PCR multiplex con las que se puede amplificar varios loci microsatélite simultáneamente a partir de una muestra minúscula. El polimorfismo STR, entre dos individuos y/o entre los dos alelos de un mismo individuo, surge porque el número de repeticiones que forma cada alelo no es el mismo.

El análisis de fragmentos se realiza mediante una electroforesis, que en este caso es capilar y automática, en la que un láser nos identifica los fragmentos que hemos obtenido de cada muestra en la amplificación. La electroforesis capilar la llevamos a cabo en el 3130 Genetic Analyzer de Applied Biosystems ${ }^{\circledR}$. Los datos son analizados con el software GeneMapper ${ }^{\circledR}$ (Applied Biosystems ${ }^{\circledR}$ ). Estos datos se muestran en un electroferograma de picos correspondientes a cada STR. El conjunto de los STR nos dará el perfil genético de la muestra. En Estados Unidos se basan en un total de 13 loci para determinar un perfil genético individual. Allí, la información de estos perfiles se encuentra almacenada en bases de datos de ADN tales como el CODIS (Combined DNA Index System). El sistema británico utiliza bases de datos con perfiles de ADN de STR de 10 loci (NDNAD). Los datos proporcionados por estos loci están aceptados por la European Network of Forensic Science Institutes (ENFSI) y por organizaciones de la Interpol ${ }^{5,7,8}$.

De los STR del AmpFlSTR ${ }^{\circledR}$ IdentifilerTM PCR Amplification Kit constituyen el sistema CODIS los siguientes: CSF1PO, D3S1358, D5S818, D7S820, D8S1179, D13S317, D16S539, D18S51, D21S11, FGA, TH01, TPOX y vWA. Pero además este kit proporciona información sobre otros tres loci más: D2S1338, D19S433 y el locus de la amelogenina (marcador de sexo).

\section{Valoración probabilística}

Una vez que se obtiene el perfil genético ${ }^{1,3}$, éste pasa por un proceso de cotejo. Se coteja el perfil genético obtenido con bases de datos como el CODIS, valorando si hay coincidencias o no. La no coincidencia implica la exclusión mientras que si es coincidente habría que hacer una interpretación estadística que requiere a su vez de estudios poblacionales con la estimación de las frecuencias alélicas de los marcadores genéticos empleados. Se calcula el poder de coincidencia y el likelihood ratio (LR).

Nuestro caso sería más sencillo ya que cotejaríamos los perfiles obtenidos con los obtenidos de las muestras recogidas en nuestro Servicio.

\section{Elaboración del informe}

Finalmente se emite un informe médico-legal.

Estas etapas tienen un precedente básico que es la correcta recogida de muestras y el envío de los vestigios al laboratorio. Las condiciones en las que llegan las muestras no siempre son las mejores para extraer el ADN. Aquí entra la denominada «cadena de custodia» de los vestigios que es de suma importancia en este proceso de identificación.

Ejemplo de una determinación de huella genética con AmpFISTR ${ }^{\circledR}$ Identifiler ${ }^{\mathrm{TM}}$ PCR Amplification Kit en la que podemos ver un individuo con el genotipo de la figura 1.

Cada muestra presentará un perfil genético o conjunto de alelos determinado. Para el caso de arriba, esos alelos son: 13 (D8S1179), 30 (D21S11), 11 (D7S820), 10/12 (CSF1P0), 14/15 (D3S1358), 8/9.3 (TH01), 11 (D13S317), 11/12 (D16S539), 19/23 (D2S1338), 14/15 (D19S433), 17/18 (vWA), 8 (TPOX), 15/19 (D18S51), X (amelogenina), 11 (D5S818) y 23/24 (FGA).

El cotejo de dicho perfil nos indicará la probabilidad de su exclusión o no en un delito, por ejemplo.

\section{AGRADECIMIENTOS}

Al Teniente Coronel José Ma Delgado Pérez.

Al Servicio de Anatomía Patológica del Hospital Central de la Defensa «Gómez Ulla» de Madrid donde se desarrolla tan interesante actividad. 
M. ${ }^{a}$ L. Marqués Negredo, et al. Identificación sanitaria: la huella genética

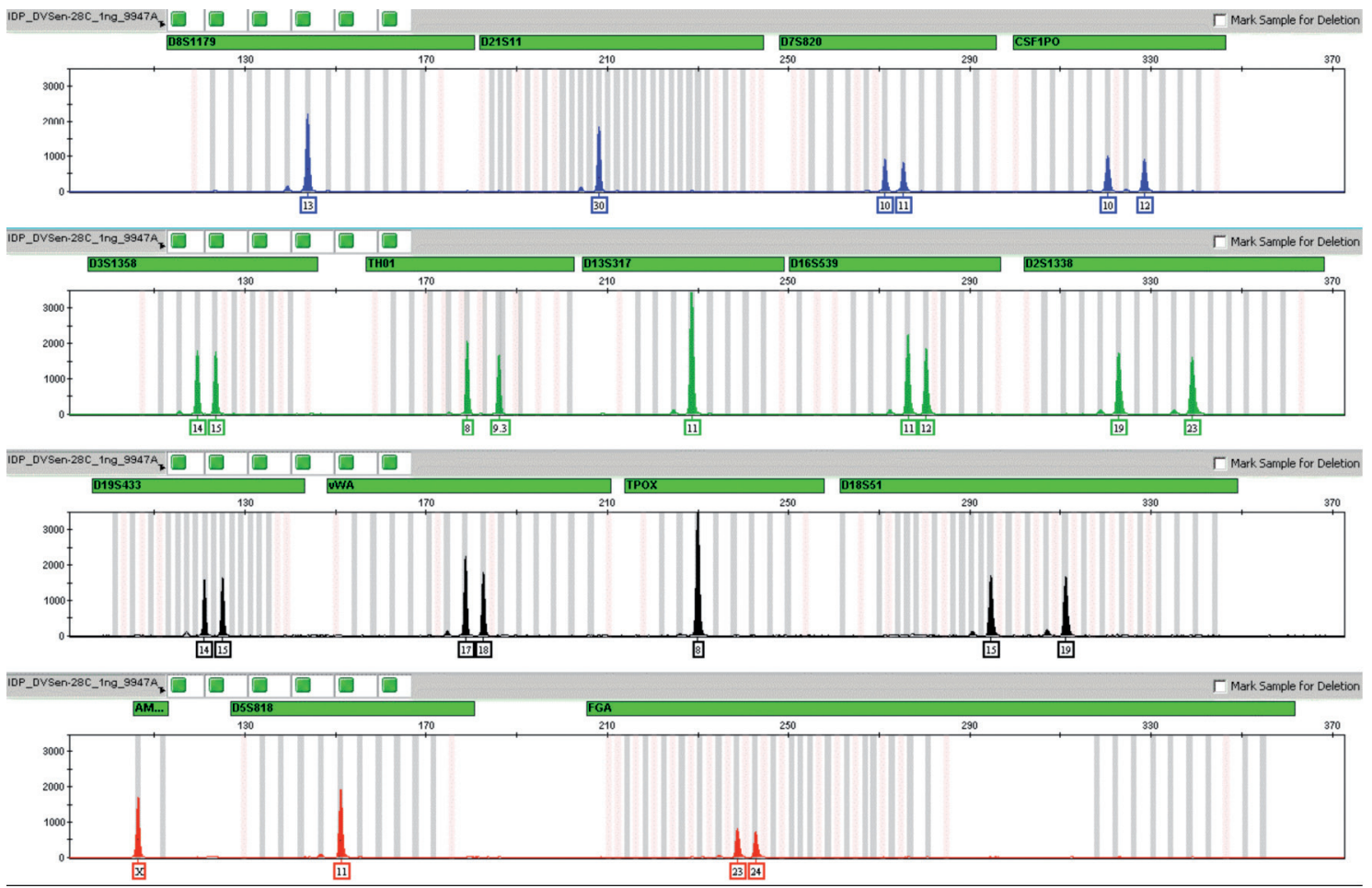

Figura 1. Análisis de $1 \mathrm{ng}$ del ADN 9947A, usado como control, amplificado con el kit AmpFlSTR ${ }^{\circledR}$ Identifiler $^{\mathrm{TM}}$ Plus y analizado en el analizador genético 3130xl de Applied Biosystems ${ }^{7}$.

\section{BIBLIOGRAFÍA}

1. Curso Teórico de introducción a la Genética Forense. $1^{\text {a }}$ Edición. 16-17 Diciembre 2009. Laboratorio de Genética Forense y Genética de Poblaciones. Departamento de Toxicología y Legislación Sanitaria. Facultad de Medicina. Universidad Complutense de Madrid. SIGEN. COBCM.

2. Luque J, Herráez A. Texto Ilustrado de Biología Molecular e Ingeniería Genética. Conceptos, Técnicas y Aplicaciones en Ciencias de la Salud. 2001 Ediciones Harcourt, S.A.. ISBN:84-8174-505-7.

3. http://www.um.es/biomytiotec/web/Seminarios/2008/papers/MV_Lareu_clase_genetica_forense.pdf

4. Biología Molecular. Curso on-line de la Fundació IL3-UB. Instituto de Formación Continua. Universitat de Barcelona. 2009.

5. Applied Biosystems 3130xl Genetic Analyzer. Bea Cabot. Diciembre 2009. User's Guide. Applied Biosystems ${ }^{\circledR}$
6. http://es.wikipendia.org/wiki/Huella_de_ADN.

7. AmpFISTR Identifiler Plus PCR Amplification Kit. User's Guide. Applied Biosystems $^{\circledR}$

8. http://en.wikipendia.org/wiki/CODIS

9. Sipes DE, Harris JA, Bethune MT, Cotton RW. Validation of the AmpFISTR ${ }^{\circledR}$ Identifiler ${ }^{\mathrm{TM}}$ PCR Amplification Kit using the ABI Prism ${ }^{\circledR} 310$ Genetic Analyzer. Orchid Cellmark, Germantown, MD 20876.

10. Patrick J. Collins, BA, Hennessy LK, Leibelt GS, Rhonda K, Rody MP, Reeder DJ, Foxall PA. Developmental Validation of a Single-Tube Amplification of the 13 CODIS STR Loci, D2S1338, D19S433 and Amelogenin: The AmpFISTR ${ }^{\circledR}$ Identifiler $^{\mathrm{TM}}$ PCR Amplification Kit. J Forensic Sci, 2004; 29(6): Paper ID JFS2002195. Available online at: www.astm.org.

11. http://en.wikipendia.org/wiki/Short_tandem_repeat.

12. Conferencia sobre «Conceptos en Genética y Cáncer». Ma Luisa Martín Ramos. Dra en Biología. Servicio de Genética. Hospital «12 de Octubre» de Madrid. 